\title{
Surface movement and deformation characteristics due to high- intensive coal mining in the windy and sandy region
}

\author{
Zhenqi Hu$^{1} \cdot$ Chao Chen ${ }^{1} \cdot \mathrm{Wu} \mathrm{Xiao}^{1} \cdot$ Xinjing Wang $^{2} \cdot$ Mingjie Gao $^{1}$
}

Received: 4 August 2016/Revised: 15 August 2016/Accepted: 30 August 2016/Published online: 30 September 2016

(C) The Author(s) 2016. This article is published with open access at Springerlink.com

\begin{abstract}
As China's energy strategy moving westward, the surface movement and deformation characteristics due to high-intensive coal mining in the windy and sandy region become a research hotspot. Surface movement observation stations were established to monitor movement and deformation in one super-large working face. Based on field measurements, the surface movement and deformation characteristics were obtained, including angle parameters, subsidence prediction parameters, etc. Besides, the angle and subsidence prediction parameters in similar mining areas are summarized; the mechanism of surface movement and deformation was analyzed with the combination of key stratum theory, mining and geological conditions. The research also indicates that compared with conventional working faces, uniform subsidence area of the subsidence trough in the windy and sandy region is larger, the trough margins are relative steep and deformation values present convergence at the margins, the extent of the trough shrink towards the goaf and the influence time of mining activities lasts shorter; the overlying rock movement and breaking characteristics presents regional particularity in the study area, while the single key stratum, thin bedrock and thick sand that can rapidly propagate movement and deformation are the deep factors, contributing to it.
\end{abstract}

Keywords Windy and sandy region · High-intensive mining $\cdot$ Surface movement and deformation $\cdot$ Key stratum

\section{Introduction}

Underground coal mining resulted in the overburden collapse and deformation, furthermore, caused the movement and deformation of the land surface (Gray 1990; Hu and Xiao 2013, 2014a, b, c), which are the main forms of the mining impact to the eco-environment and is crucial for ecological restoration (Hu et al. 2014a, b, c; Xiao et al. 2014a, b). There are abundant coal resources in the windy and sandy region of northwestern China, and its occurrence

Zhenqi Hu

huzq@cumtb.edu.cn

1 Institute of Land Reclamation and Ecological Restoration, China University of Mining and Technology (Beijing), Beijing, China

2 College of Resource and Environment, North China University of Water and Electric Power, Zhengzhou, China characteristics, including shallow cover depth, thin bedrock, overlying hard strata, near-flat seam with thick sand on the surface, which are suitable for high-intensive coal mining characterized with large advancing speed, high recovery rate and big width/depth ratio, are significantly different from those in eastern China ( $\mathrm{Du}$ 2010; Zhang et al. 2011; Liu 2014). The coal mines in the eastern China has long been the major mining areas (Xiao and $\mathrm{Hu} 2014$ ), as China's energy strategy moving westward, high-intensive coal mining is and will be in operation in the Shendong coalfield where the ecological environment is fragile, thus, the surface movement and deformation due to coal mining will be a prominent ecological problem, which poses a great threat to the ecological safety, however, few studies regarding the windy and sandy region can be referred (Wang et al. 2015). With the continually innovation of fully high-intensive mechanized technology, the high-intensive coal mining with super-large working (SLW) face has been widely applied in large coal bases due 
to its advantages as diverse as large panel dimensions, large advancing speed $(10 \mathrm{~m} / \mathrm{d}$ at least), high recovery rate, etc. (Wang 2014). Wu et al. (2010) considered that the large working face reduced the disturbance magnitude compared with the conventional working face in Yanzhou coalfield. Tan et al. (2008) had revealed the surface movement and deformation characteristics of a large working face in eastern China based on field measurements. The research of Teng and Liu (2002) in Wuyang coal mine with high-intensive mining shows similar results to $\mathrm{Wu}$. $\mathrm{Li}$ (2010) applied the 3D laser scanning technology in the research on the surface movement characteristics in Yanzhou coalfield, found the convergence of deformation values. Besides, the numerical simulation of mining subsidence cracks is also a research focus (Peng et al. 2009, 2010; Zhang et al. 2011; Liu et al. 2015). The methods of simulation and calculation have been recently applied in the research on overlying strata movement characteristics, ground pressure behavior, subsidence prediction associated with high-intensive mining in the windy and sandy region (Huang 2002; Wang et al. 2007; Xuan 2008; Fan et al. 2011; Ju et al. 2015). Sun (2008) compared the surface movement and deformation characteristics in the windy and sandy region with that in the loess area by using numerical simulation, Tang et al. (2007) proposed a subsidence prediction model and a parameter confirmation method in the windy and sandy region based on the stochastic medium theory. Gu et al. (2014) has obtained the surface movement and deformation characteristics under the condition of subcritical extraction in similar coal mines. The researches concerning the surface movement and deformation characteristics under the condition of highintensive mining increase annually, however, there are still some unsatisfactory phenomena and need to conduct further researches, those are: (1) many achievements in the similar mining and geological conditions are mostly in the eastern China, theories and methods are more mature, and less researches concerned about the surface movement and deformation characteristics under the condition of critical extraction in the windy and sandy region; (2) most of the existing researches in the windy and sandy region are based on the numerical simulation and functional model, lacking comparison with measured data; (3) It is still unclear whether there is generality of surface movement and deformation characteristics under the condition of highintensive mining, with certain mining and geological conditions in the windy and sandy region.

Based on above, surface movement observation stations were established in the 12406 super-large working (SLW) face in Bulianta coal mine, to get a few phases of measured data based on the long-term dynamic monitoring, and the surface movement and deformation characteristics in the typical windy and sandy region were revealed. The angle parameters have been acquired after the analysis of the data, and the parameters of probability integral method have also been acquired via non-liner fitting of Origin software, the generalities of the surface movement and deformation characteristics are concluded after comparison and analysis of the surface movement and deformation characteristics and parameters under similar conditions, which would provide theoretical reference for land reclamation and ecological restoration under the condition of high-intensive mining in the windy and sandy region.

\section{Study area}

\subsection{Physical geography situation}

The Bulianta coal mine of Shendong coalfield, located in Ordos, Inner Mongolia (Fig. 1). The geographical position is for the north latitude $39^{\circ} 18^{\prime} 31^{\prime \prime}-39^{\circ} 22^{\prime} 43^{\prime \prime}$, east longitude $110^{\circ} 4^{\prime} 16^{\prime \prime}-110^{\circ} 10^{\prime} 18^{\prime \prime}$, and the coal mine covers an area of $36.70 \mathrm{~km}^{2}$ with an altitude from 1130 to $1260 \mathrm{~m}$ above sea level.

Shendong coal field is located in the transition zone of Ordos Plateau and Muus Desert, and the surface is covered by quaternary loose windy bed, with hilly topography, terrain is relatively flat, with high elevation in the west and lower in the east. The study area has a semi-arid and desert plateau continental climate, with mean annual precipitation of $357 \mathrm{~mm}$, maximum annual precipitation of $531 \mathrm{~mm}$, and minimum annual precipitation of $195 \mathrm{~mm}$. More than half of the precipitation occurs during the summer (from July to September). The annual average temperature is $6.2{ }^{\circ} \mathrm{C}$, extreme minimum temperature of $-31.4{ }^{\circ} \mathrm{C}$, and the extreme maximum temperature of $36.6^{\circ} \mathrm{C}$. The average frost-free period is between 130 and 140 days. The annual sunshine hours is from 2740 to $3100 \mathrm{~h}$. Potential yearly evaporation is around $2163 \mathrm{~mm}$, about 6 times of the annual evaporation. In absence of earthquake date, according to the China earthquake intensity zoning map, the earthquake intensity degree of the study area is below 6.

\subsection{Mining and geological conditions}

This paper takes the 12406 SLW face of Bulianta coal mine as the study object, which has commenced to mine the $1^{-2}$ coal seam on Apirl and completed on December, 2011.The virgin zone lied on uphill, and the adjacent old goaf lied on the downhill. The SLW face mined $1^{-2}$ coal seam, with a dip angle from $1^{\circ}$ to $3^{\circ}$, which is stable and belongs to flat seams. The thickness of the coal seam ranges from $4.19 \mathrm{~m}$ to $5.56 \mathrm{~m}$ with an average thickness of $4.81 \mathrm{~m}$. The depth of the coal seam was from $190 \mathrm{~m}$ to $220 \mathrm{~m}$. The 


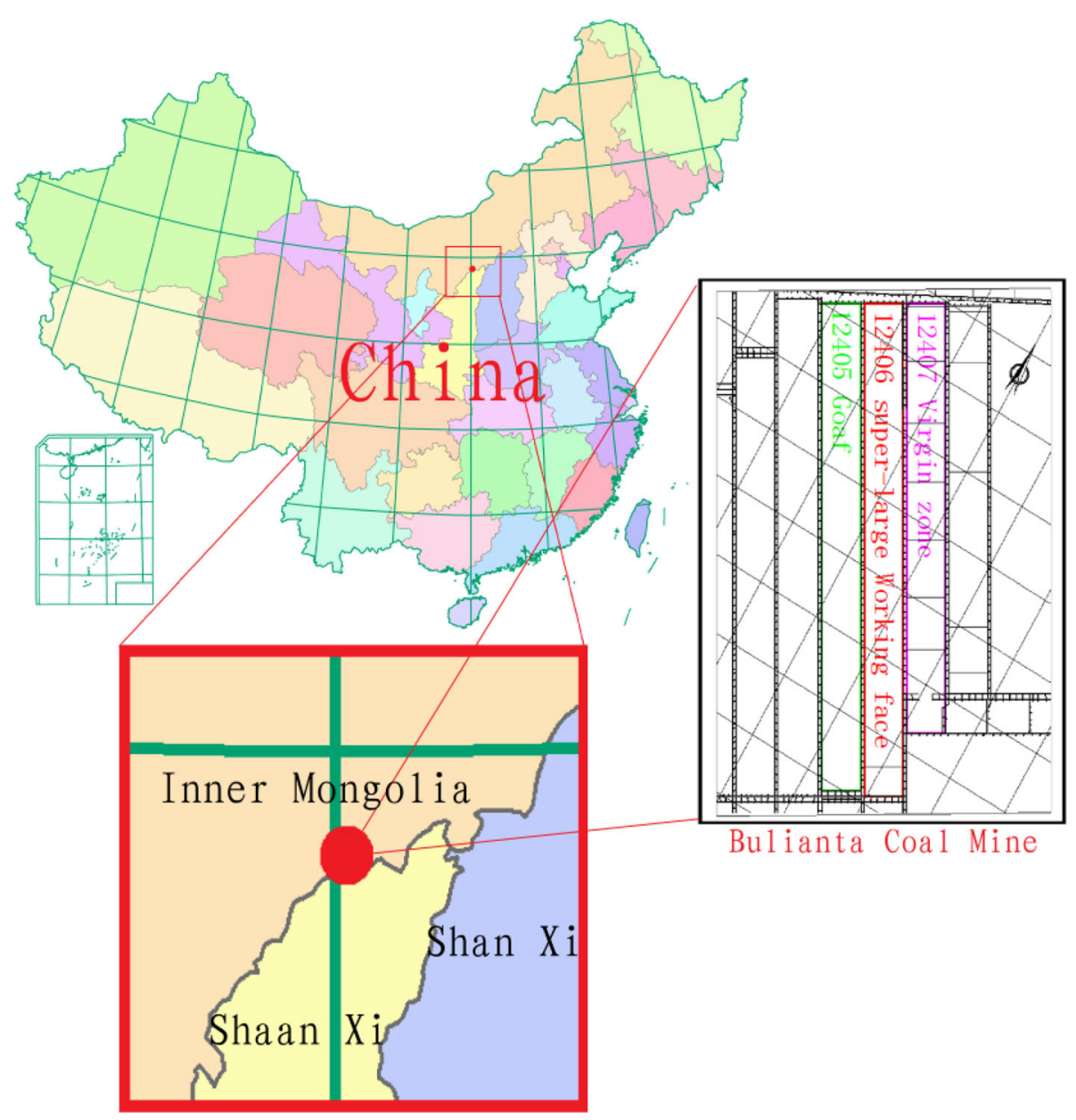

Fig. 1 Location of the study area

overburden was composed of 180-200 m medium-hard rock which is partial to hard and 8-27 m quaternary loose bed, a typical geological section was shown in Fig. 2. Surface is covered by loose sandy soil with strong flow characteristic and thin desert soil crusts. The SLW face adopted longwall fully-mechanized and full-seam mining method, the roof of which is managed through the all fall method, the longwall panel was $3592 \mathrm{~m}$ long and $300.5 \mathrm{~m}$ wide, average mining thickness $(M$, meter) is $4.5 \mathrm{~m}$, with advancing speed of $12 \mathrm{~m} / \mathrm{d}$. At present, all robbing work has been finished.

\section{Materials and methods}

In order to monitor the surface movement and deformation characteristics, surface movement observation stations were established by adopt the layout method of profile striation observation station according to the situation of landform and terrain and the mining geological conditions in the SLW face (Zou et al. 2003). In consideration of critical extraction that can be achieved in the longitudinal direction, the observation points were just needed to be deployed in the critical extraction region, therefore half loaf of observation line was layout along the longitudinal main section while a loaf of observation line was layout along the transverse main section, two observation line are perpendicular to each other. According to mining subsidence theory and the data of similar mine areas (Zou et al. 2003; Wang 2014), the area that $300-400 \mathrm{~m}$ away to the stopping line can achieve critical extraction when the mining depth is approximately $200 \mathrm{~m}$. Based on the above research, observation points were began to be layout $400 \mathrm{~m}$ away from the open-off cut outside the SLW face, and it ended until $500 \mathrm{~m}$ away from the open-off cut above the longitudinal main section, the distance between each points is $20 \mathrm{~m}$ and thus the total length of the longitudinal observation line is $900 \mathrm{~m}$. In order to guarantee the deformation observation results of the transverse direction, the starting point should be layout $400 \mathrm{~m}$ away to the boundary of the SLW face, thus the total length of the transverse direction is $1100 \mathrm{~m}$. Considering the effect of 


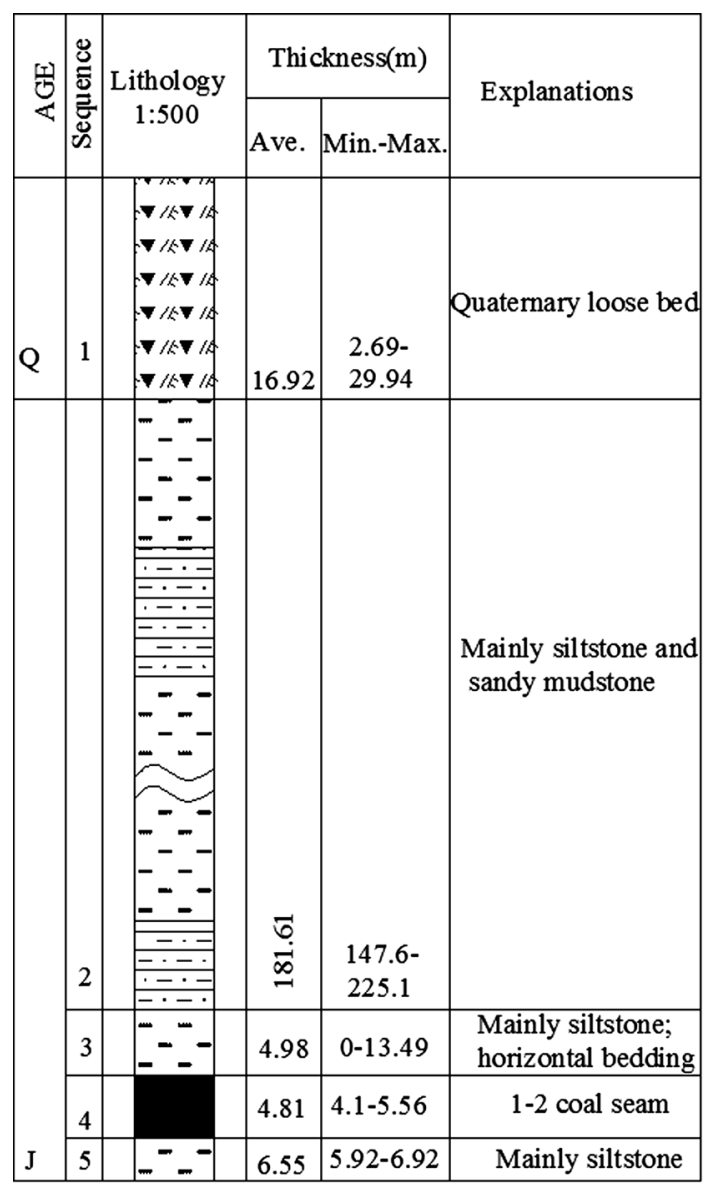

Fig. 2 The lithological column of No. 12406 SLW face

the old adjacent goaf, more specifically, the distance between each points is $30 \mathrm{~m}$ on the old adjacent goaf side, and $20 \mathrm{~m}$ on the side without mining. The observation points are cement column with a depth of $1 \mathrm{~m}$, which were made in the field, of which the port is $10 \mathrm{~cm} \times 10 \mathrm{~cm}$ while the bottom is $30 \mathrm{~cm} \times 30 \mathrm{~cm}$, in spite of this, the part of the cement column on the ground ranges from $5 \mathrm{~cm}$ to $10 \mathrm{~cm}$. According to the requirement of the Coal mine measurement specification, comprehensive measurement and subsidence measurement had been conducted six times and eleven times, respectively. The layout situation of the surface movement observations is shown as Fig. 3.

\section{Results and discussion}

\subsection{Data analysis}

(1) The analysis of subsidence data

According to the observation data, the subsidence curve of longitudinal direction and transverse direction can be obtained respectively (Gao 2012; Wang 2014; Wang et al. 2015), as shown in Fig. 4.
As shown in Fig. 4a, the subsidence areas are becoming larger with the continuous advancing. The range and values of subsidence gradually increased, and then subjected to be stable without any abnormal phenomenon, which followed the general laws of mining subsidence. However, subsidence curve has its specific characteristics, when comparing with those in the mid-eastern China mining areas, such as Yanzhou mining area (Wu et al. 2010), which are: (1) the uniform subsidence areas were relatively larger in subsidence basin and the trough margins was more sharp. There was an obvious difference of the subsidence curve, which showed more convergence at the two ends of openoff cut, leading to the extent of the trough towards the goaf. The subsidence value of $10 \mathrm{~mm}$ was taken as the boundary of the affected mining areas, and the boundary was approximately $1.0 H$ ( $H$ : the average mining depth, meter) away to the open-off cut. (2) when the working face was approximately $1.5 \mathrm{H}$ away to the observation points, the subsidence value reached the peak, and then maintained stable. During this period, the affected time lasted 27 days where around the observation points. The reason is that with the increasing advancing speed, the time of surface deformation continuously decreased, which speed up the recovery process of surface ground. As Fig. $4 \mathrm{~b}$ shows, the process of surface deformation and the shape of the distribution in the transverse direction followed those in the longitudinal direction basically. Because the subsidence was affected by the adjacent old goaf, the subsidence values and range on the side of old goaf was larger, it is safe to indicate that multi-disturbance can result in the increase of subsidence values and range. In additional, inclination deformation values concentrated at the two sides of the mining boundary due to high-intensive mining, while inclination deformation outside the mining boundary decreased sharply, nevertheless, curvature deformation followed the general laws of mining subsidence.

\section{(2) The analysis of horizontal movement data}

As shown in Fig. 5a, the positive horizontal movement was larger than negative horizontal movement, the horizontal movement towards goaf was larger than that towards coal pillars, and the horizontal movement basically approached to goaf, and the pillar which is $1.5 \mathrm{H}$ away to the open-off cut occurred horizontal deformation. The maximum horizontal movement occurred in the observation point which is $0.2 \mathrm{H}$ away to the open-off cut, and the maximum negative horizontal movement occurred in the observation point which is $0.5 \mathrm{H}$ away to the open-off cut. The horizontal movement towards the mining direction was larger than that towards open-off cut overall, and the horizontal movement was near the open-off cut (Fig. 5a). $X$ direction of the maximum movement point of transverse line was towards the mining direction, and $Y$ direction was 


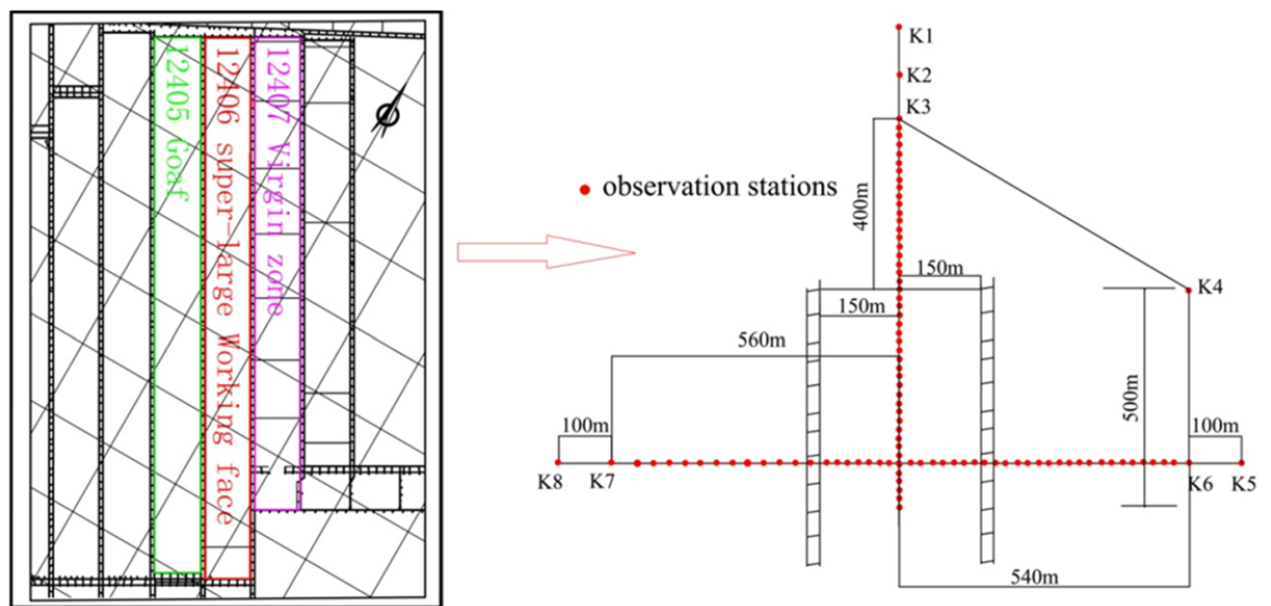

Bulianta Coal Mine

Fig. 3 Layout plan of some SLW faces and the observation stations in 12406 SLW face

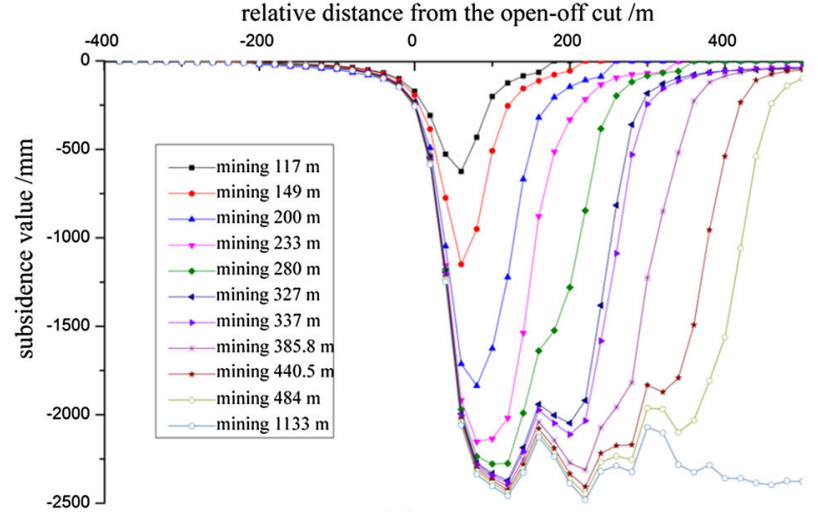

(a)

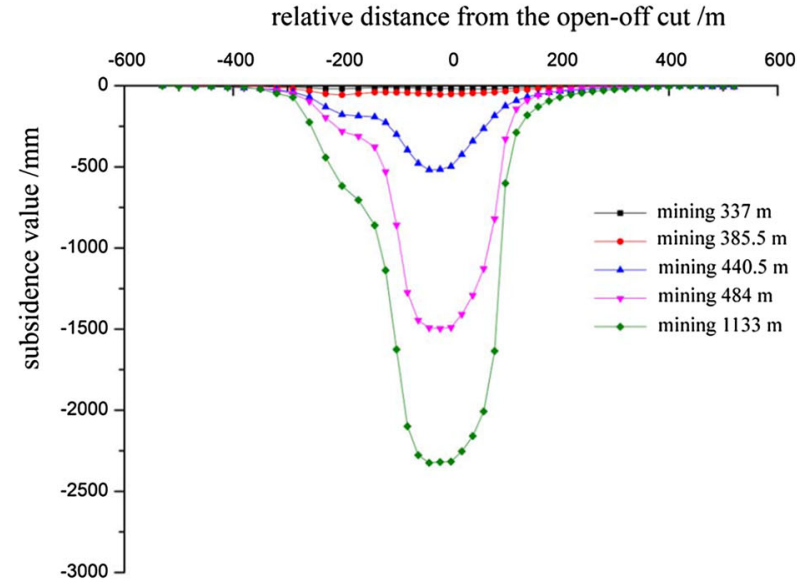

(b)

Fig. 4 a Subsidence curve of longitudinal direction, b Subsidence curve of transverse direction

towards the old goaf, which was resulted from that the surface near the old goaf has experienced primary

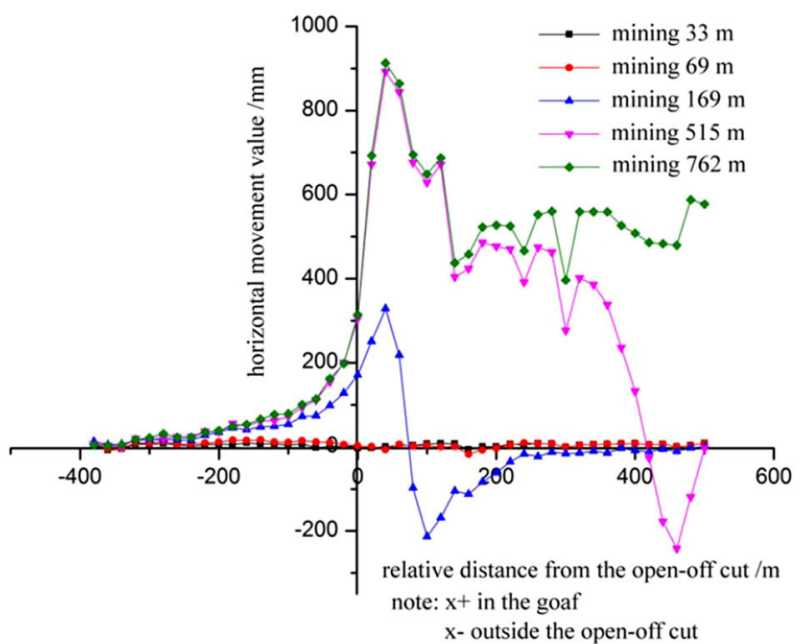

(a)

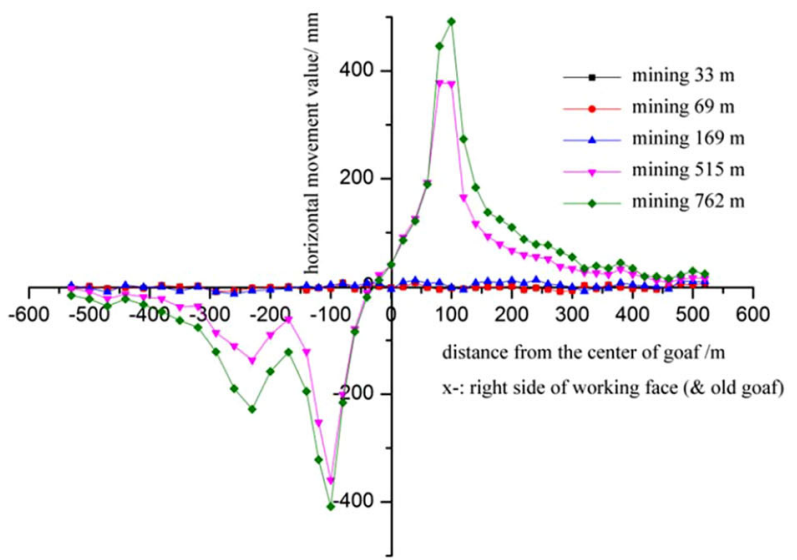

(b)

Fig. 5 a Horizontal movement curve of longitudinal direction, b Horizontal movement curve of transverse 
subsidence. When mining began in the SLW face, subsidence values were relatively small, while the general subsidence values was still larger than that in the virgin zone, and the horizontal movement was more complex comparing with that in the new mining areas. The horizontal movement changes were relatively obvious in which the range is approximately $1.2 \mathrm{H}$ away to the open-off cut, with the horizontal displacement of uphill and downhill pointing to the center of the SLW face. The two sides of surface in the transverse direction exhibited a trend pointing to the center. In addition, the horizontal deformation of longitudinal direction concentrated on the open-off cut and the advancing direction of the SLW face, however, the horizontal deformation in virgin zone side of the transverse direction was generally larger than that in the goaf (Fig. 5b). Therefore, the point with the critical deformation value is closer to the mining boundary, and the damage range reduced further (Gao 2012; Wang 2014; Wang et al. 2015).

\section{(3) Calculation of surface angle parameters}

According to the theory of mining subsidence (Zou et al. 2003), the boundary of the trough is generally described by the parameters of the angle, such as the angle of critical extraction, angle of greatest subsidence, limit angle, angle of displacement and angle of crack. Because of the insufficiency of observation data in the longitudinal direction, moreover, the coal seam belongs to the flat seam, which is stable, therefore, the angle parameters of transverse direction were mainly analyzed. Based on the analysis of the subsidence curve, horizontal movement curve and field measured data, the angle parameters of the SLW face obtained are shown in Table 1 (Gao 2012; Wang 2014).

According to the above parameters of the angle, the distribution range of the surface movement and cracks exhibited a trend of internal shrinkage to the adjacent goaf.

(4) Probability integral fitting for parameters based on the Origin software

There are some limitations in the method that based on the definition of the predicting parameters in the probability integral method and the field measured data to calculate subsidence parameters, while the Origin software

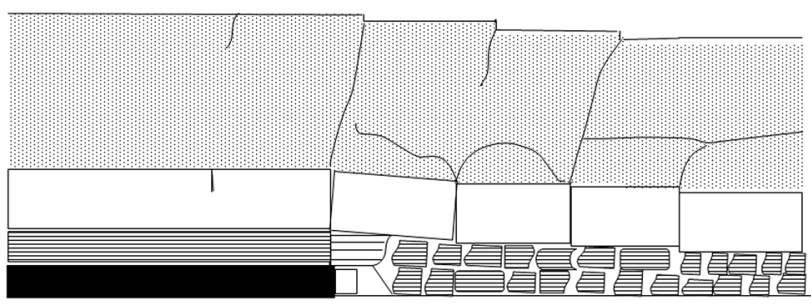

Fig. 6 Overall cut and fall of the overburden and step convergence has a strong user-defined function, the predicting parameters are obtained via combining theoretical formula of the probability integral method. The fitting progress of the Origin software with the application of probability integral method is described as follows (Gao 2012).

subsidence:

$W(x)=W_{0} \sum \int_{0}^{D} \frac{1}{r} \exp \left(-\pi \frac{(x-s)^{2}}{r^{2}}\right) d s$

tilting:

$i(x)=\frac{W_{0}}{r}=e^{-\pi \frac{x^{2}}{r^{2}}}$

curvature:

$k(x)=-\frac{2 \pi W_{0}}{r^{3}} x e^{-\pi \frac{x^{2}}{r^{2}}}$

horizontal movement:

$U(x)=b r i(x)=b W_{0} e^{-\pi \frac{x^{2}}{r^{2}}}$

where, $W_{0}$ is the surface maximum subsidence value (critical extraction); $D$ is the mining length; $s$ is the mining unit; $r$ is the main influence radius; $b$ is the horizontal movement coefficient.

Whether the underground ore body reach critical extraction or not can be determined by the following formula.

$n_{1}=K_{1} \frac{D_{1}}{H_{0}}, \quad n_{3}=K_{3} \frac{D_{3}}{H_{0}}$

In the formula, $K_{1}$ and $K_{3}$ are the coefficients which are smaller than $1, D_{1}$ and $D_{3}$ respectively, are the length of transverse and longitudinal in the actual goaf, when $n_{1}$ and $n_{3}$ are larger than 1 , it reached critical extraction, on the contrary, it is subcritical extraction, the value of $K_{1}$ and $K_{3}$ are equal to 0.7 .

On the condition of SLW face, $D_{1}=300.5 \mathrm{~m}$, $D_{3}=3592 \mathrm{~m}, H_{0}=188 \mathrm{~m}$, the calculated $\mathrm{n}_{1}$ and $\mathrm{n}_{3}$ via the formula were larger than 1, namely the SLW surface reached critical extraction.

The parameters are calculated via multiple iterations, the fitting results are shown in Table 2 (Gao 2012; Wang 2014).

\subsection{The generality of surface movement and deformation}

After referring to the published papers (Xu et al. 2005; Yi 2008; Du 2010; Gao 2012; Wang 2014), the mining geological conditions, parameters of surface movement angle and probability integral method of the selected similar 


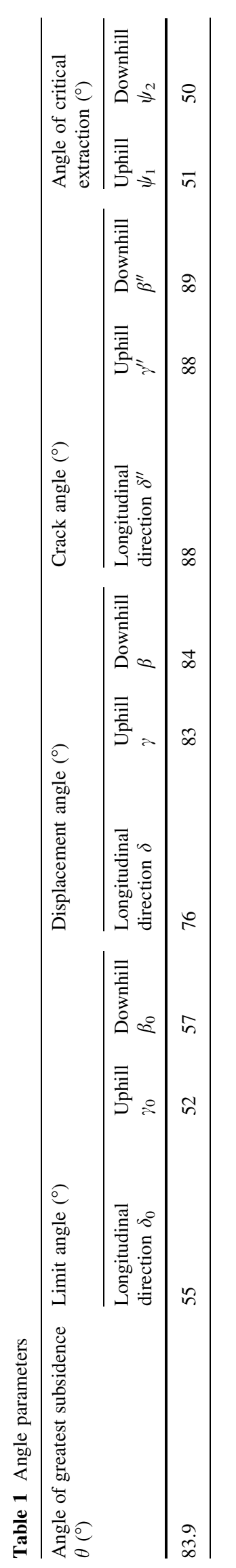

SLW face are summarized as shown in the following Tables 3, 4, and 5 .

(1) Mining and geological conditions of similar SLW faces

According to the Table 3, the better occurrence condition of coal resource is suitable for high-intensive coal mining in the windy and sandy region.

(2) The generality of static angle parameters

The angle parameters of similar mining areas are summarized in the table, the angle parameters showed some generality despite the differences among them.

(i) The limit angles of each subsidence basin are basically identical, the range of the boundary is approximately equal to the $H$. For the same SLW face, the limit angle of longitudinal direction is approximately equal to those of uphill (downhill), and exhibits a trend that the larger the mining depth the greater the limit angle, the larger mining thickness the smaller the limit angle, the thicker the topsoil the smaller the limit angle. On the condition that the mining depth of summarized SLW faces are approximately equal to each other, the limit angle decreases with the reduction of the ratio $(H /$ $M$ ), thus the subsidence basin is relatively larger.

(ii) On the condition that the ratio is larger than 30 , the displacement angle is generally larger than $75^{\circ}$, with the concentrated movement deformation, moreover, the displacement boundary become smaller, pointing to the goaf; If the ratio is smaller than 30, the displacement angle would decrease obviously, which can be attributed to that the ratio is small, the fracture height of overlying strata increased and the fractured zone is easy to propagate to surface, severe destruction of overlying strata above the coal pillar, and the expansion of the displacement boundary. As to the same mining unit, displacement angles of uphill (downhill) are slight larger than that of longitudinal direction.

(3) The generality of the parameters of probability integral method

Parameters of probability integral method of similar SLW faces in windy and sandy region are summarized in Table 5, there are some generality as follows.

(1) In the study area, the subsidence coefficients are basically between 0.55 and 0.61 , and it is relatively small, which can be attributed to the following factors: (1) The lithology of overlying strata is medium hard and hard; (2) The ratio between bedrock ply and top soil thickness is relatively large, which can reach 10 generally. As shown above, the 
Table 2 Parameters of probability integral method

\begin{tabular}{llll}
\hline Subsidence coefficients $q$ & Horizontal movement factor $b$ & Tangent of major influence angle tan $\beta$ & Deviation of inflection point $s$ (m) \\
\hline 0.55 & 0.26 & 2.51 & 40 \\
\hline
\end{tabular}

Table 3 Mining and geological conditions of similar SLW faces in the windy and sandy region

\begin{tabular}{|c|c|c|c|c|c|c|}
\hline SLW face & $\begin{array}{l}\text { Bulianta } \\
12406\end{array}$ & $\begin{array}{l}\text { Cuncaota } \\
22111\end{array}$ & $\begin{array}{l}\text { Liuta } \\
12106\end{array}$ & $\begin{array}{l}\text { Daliuta } \\
52304\end{array}$ & $\begin{array}{l}\text { Daliuta } \\
1203\end{array}$ & $\begin{array}{l}\text { Bulianta } \\
31401\end{array}$ \\
\hline Average mining depth $H(\mathrm{~m})$ & 200 & 250 & 150 & 225 & 61 & 255.4 \\
\hline Average mining thickness $M(\mathrm{~m})$ & 4.5 & 2.8 & 6.9 & 6.9 & 4.03 & 4.2 \\
\hline Ratio of $H / M$ & 44.4 & 89.3 & 21.7 & 32.3 & 15.1 & 60.7 \\
\hline longitudinal length $L(\mathrm{~m})$ & 3592 & 2085 & 633 & 4547 & 938 & 4629 \\
\hline transverse length $L(\mathrm{~m})$ & 300.5 & 224 & 246.8 & 301 & 150 & 265.25 \\
\hline Topsoil thickness $h(\mathrm{~m})$ & 17 & 8 & 30 & 30 & 26.5 & l \\
\hline Average coal seam dip angle $\left(^{\circ}\right)$ & $1-3$ & 1 & 1 & $1-3$ & 0.3 & $1-3$ \\
\hline Advancing speed $C(\mathrm{~m} / \mathrm{d})$ & 12 & 9.7 & 5 & 7.4 & 2.4 & $>12$ \\
\hline
\end{tabular}

Table 4 Angle parameters of similar SLW faces in the windy and sandy region

\begin{tabular}{lllll}
\hline SLW face & Bulianta 12406 & Cuncaota 22111 & Liuta 12106 & Daliuta 52304 \\
\hline Measured limit angle of longitudinal direction $\left(^{\circ}\right)$ & 55 & 48 & 48.3 & 42.5 \\
Measured limit angle of uphill (downhill) $\left(^{\circ}\right)$ & 54.5 & 51.9 & 51.2 & 42.2 \\
Measured displacement angle of longitudinal direction $\left({ }^{\circ}\right)$ & 76 & 74.3 & 61.1 & $/$ \\
Measured displacement angle of uphill (downhill) $\left({ }^{\circ}\right)$ & 83.5 & 75.9 & 61.2 & 82 \\
\hline
\end{tabular}

Note Comprehensive limit angle and displacement angle in this table

Table 5 Parameters of probability integral method of similar SLW faces in windy and sandy region

\begin{tabular}{lllll}
\hline SLW face & Bulianta 12406 & Daliuta 1203 & Daliuta 52304 & Bulianta 31401 \\
\hline Subsidence coefficient & 0.55 & 0.59 & 0.61 & 0.55 \\
Horizontal movement factor & 0.26 & 0.29 & 0.32 & 0.127 \\
Tangent of major influence angle & 2.51 & 2.65 & 2.88 & 3.40 \\
Deviation of inflection point $S_{0}(\mathrm{~m})$ & 40 & 20.4 & 37.5 & 29 \\
Maximal subsidence velocity $(\mathrm{mm} / \mathrm{d})$ & 268 & $/$ & 430 & 540 \\
\hline
\end{tabular}

subsidence coefficient is mainly related to the geological conditions in the study area.

(2) The horizontal movement factors are basically between 0.20 and 0.30 , which accorded with the general values of other ordinary fully-mechanized working faces (Wang 2014). It is safe to conclude that a significant increase doesn't appear in the horizontal displacement due to the high-intensive mining.
(3) The tangent of major influence angle are basically between 2.51 and 3.40, which shows that the main surface deformation value is more concentrated, with a steep surface subsidence basin and there is a obvious difference of the subsidence curve at the two sides of the mining boundary pointing to the goaf, moreover, it is consistent with the field data, which can be mainly attributed to such factors as the rapid mining, the acceleration of the overburden 
subsidence velocity, the reduction of relative suspended time.

(4) The surface subsidence velocity increases obviously due to rapid mining, and it also becomes larger with the increase of the mining thickness. In the mining process, the dynamic change rate of the surface subsidence velocity is relatively large, moreover,compared with the published paper, it shortens the cycle of mining impact on the land ecological environment (Qu et al. 2009).

\subsection{The analysis of the mechanism of surface movement and deformation}

The process of the surface movement and deformation in the study area is in line with the general mining subsidence characteristics, however, on the condition of high-intensive coal mining, the law of overburden rock movement and breaking exhibits regional particularity owing to the special occurrence characteristics of coal resources in the windy and sandy region, thereby leading to the certain particularity of the surface movement and deformation characteristics. Published researches (Qian et al. 2010) indicated that there exists single key stratum structure, the lithology is hard partial to hard, which determined the particularity of the roof bedrock movement of the SLW face.

In some study areas, the fractured zone is likely to propagate to surface, and ground pressure behavior is severe, resulting in stepped subsidence (Fig. 6) (Qian et al. 2010) with larger subsidence velocity of some measured points. The subsidence curve is steep but relatively stable on the side of open-off cut, whereas the subsidence curve advanced in a larger angle on the SLW face advancing side in the mining process. When achieving critical extraction, a flat base appeared in the subsidence basin of which the range was larger than the general ones. In addition, high-intensive mining are responsible for the reduction of the abscission layer and fracture and accelerating the compaction and stability of damaged overburden, thereby reducing the overburden damage effectively ( $\mathrm{Yi}$ 2008; Du 2010; Zhang and Li 2013) and promoting the self-healing of the damaged topsoil (Hu et al. 2014a, b, c).

\section{Conclusions}

(1) The uniform subsidence area of the subsidence basin due to high-intensive coal mining in the SLW face is larger, with relative steep trough margins and concentrated deformation value, the range of the subsidence basin shrinks to the goaf with shorter influence time of mining activities, which is consistent with field observations; The angle of greatest subsidence is $83.9^{\circ}$, the limit angle of longitudinal direction and those of uphill (downhill) are $55^{\circ}, 52^{\circ}, 57^{\circ}$, respectively, the displacement angle of longitudinal direction and those of uphill (downhill) are $76^{\circ}, 83^{\circ}, 84^{\circ}$, respectively, the crack angle of longitudinal direction and those of uphill (downhill) are $88^{\circ}, 88^{\circ}, 89^{\circ}$, respectively, moreover, the angle of critical extraction of uphill (downhill) are $51^{\circ}$ and $50^{\circ}$ respectively; Among the probability integration method parameters, the subsidence coefficient, the horizontal movement factor and the tangent of major influence angle are $0.55,0.26$ and 2.51 respectively, while the deviation of inflection point is $40 \mathrm{~m}$.

(2) In the similar circumstances, the limit angles of each SLW face are basically identical, the range of the boundary is approximately equal to $H$. For the same face, the limit angle of longitudinal direction is approximately equal to those of uphill (downhill), and exhibit a trend that the larger the mining depth the greater the limit angle, the larger $M$ the smaller the limit angle, the thicker the topsoil the smaller the limit angle. In the condition that the $H$ is approximately equal to each other, the limit angle decreases with the reduction of the ratio of $H / M$, thus the subsidence basin is relatively larger; In the condition that the ratio is larger than 30 , the displacement angle is larger than $75^{\circ}$ generally, with a concentrated movement deformation value, thereby the displacement boundary becomes smaller and shrinks to the goaf; If the ratio is smaller than 30 , the displacement angle would decrease obviously. For the same SLW face, displacement angles of uphill (downhill) are slight larger than that of longitudinal direction.

(3) In the similar circumstances, the subsidence coefficients are small, mainly relating to the medium-hard overburden rock which is partial to hard; Under the condition of high-intensive coal mining, the horizontal movement factor did not increase, on the contrary, the tangent of major influence angle and the maximum subsidence velocity are relatively larger.

(4) The law of overburden rock movement and breaking exhibits regional particularity because of the condition of high-intensive coal mining and the special occurrence characteristics of coal resources, such as shallow coal seam, thin bedrock and thick sand bed in the study area, while the single key strata, the thin bedrock and thick sand bed which can rapid propagate movement and deformation are the deep factors that contribute to the certain particularity of surface movement and deformation. 
Acknowledgments Financial supports for this work, are provided by the National Natural Science Foundation of China (NSFC) \& Shenhua Group Corporation Limited key support project of the coal joint fund (U1361203) and NSFC under Grant No. 41501562. Thanks are also due to some participants for rendering assistant cooperation during studies.

Open Access This article is distributed under the terms of the Creative Commons Attribution 4.0 International License (http://creative commons.org/licenses/by/4.0/), which permits unrestricted use, distribution, and reproduction in any medium, provided you give appropriate credit to the original author(s) and the source, provide a link to the Creative Commons license, and indicate if changes were made.

\section{References}

Du SZ (2010) The rule of the overlying strata movement and their phytoremediation technology after large-scale underground mining operation in Shendong coal mine area. China University of Mining and Technology (Beijing), Beijing

Fan GW, Zhang DS, Ma LQ (2011) Overburden movement and fracture distribution induced by longwall mining of shallow coal seam in the Shendong coalfield. J China U Min Technol 40(2):196-202

Gao MJ (2012) Research the law of ground movement after mining in shallow large-scale in Shendong coal mine area. China University of Mining and Technology (Beijing), Beijing

Gray RE (1990) Mining subsidence-past, present, future. Int J Min Geol Eng 8(4):400-408

Gu SC, Wang EB, Xiong JQ (2014) Field measurement study on movement law of insufficient mining movement surface ground above shallow depth seam. Coal Eng 6:99-102

Hu ZQ, Xiao W (2013) Optimization of concurrent mining and reclamation plans for single coal seam: a case study in northern Anhui, China. Environ Earth Sci 68(5):1247-1254

Hu ZQ, Wang XJ, He AM (2014a) Distribution characteristic and development rules of ground fissures due to coal mining in windy and sandy region. J China Coal Soc 39(1):11-18

Hu ZQ, Yang GH, Xiao W, Li J, Yang YQ, Yu Y (2014b) Farmland damage and its impact on the overlapped areas of cropland and coal resources in the eastern plains of China. Resour Conserv Recy 86:1-8

Hu ZQ, Long JH, Wang XJ (2014c) Self-healing, natural restoration and artificial restoration of ecological environment for coal mining. J China Coal Soc 39(8):1751-1757

Huang QX (2002) Ground pressure behavior and definition of shallow seams. Chin J Rock Mech Eng 21(8):1174-1177

Ju JF, Xu JL, Zhu WB (2015) Longwall chock sudden closure incident below coal pillar of adjacent upper mined coal seam under shallow cover in the Shendong coalfield. Int J Rock Mech Min Sci 77:192-201

Li L (2010) Study on damage mechanics and repair methods of embankment under the conditions of high-strength underground mining. China University of Mining and Technology, Xuzhou

Liu H (2014) The development law and treatment technology of ground fissures due to underground mining in Loess Hilly Area of Western China. China University of Mining and Technology, Xuzhou

Liu H, Deng KZ, Lei SG, Bian ZF (2015) Mechanism of formation of sliding ground fissure in loess hilly areas caused by underground mining. Int J Min Sci Technol 25(4):553-558

Peng YW, Qi QX, Li HY, Deng ZG (2009) Numerical simulation and analysis on influencing factors of fractured zone height of highstrength underground mining. J China Coal Soc 34(2):145-149
Peng YW, Qi QX, Wang YG, Deng ZG, Li HY, Li CY (2010) Study of field measurement of mining-induced coal fracture field and its application. China J Rock Mech Eng 29(s2):4188-4193

Qian MG, Shi PW, Xu JL (2010) Mining pressure and strata control. China University of Mining and Technology Press, Xuzhou

Qu JF, Li G, Zhang SL, Li KX, Zhang P (2009) Study on exploitation and utilization of water and land resources to mining subsidence in the plain area of higher underground water. China Min Mag 18(3):64-66

Sun HX (2008) Rules comparison of surface movement induced by coal mining under aeolian sand and loess. Coal in Technol 1:6-9

Tan ZX, Wang ZS, Li YJ, Sun XM, Deng KZ (2008) Field research on ground subsidence rules of intensive fully-mechanized mining by sublevel caving. J Min Saf Eng 1:59-62

Tang FQ, Yao WQ, Xia YC (2007) Prediction method of ground subsidence for coal mining in seam under thin base rock. Coal Sci Technol 6:103-105,66

Teng YH, Liu KG (2002) Research on surface ground displacement law under high tension coal mining conditions in Wuyang Mine. Coal Sci Technol 4:9-11,15

Wang JA, Zhao ZH, Hou ZY (2007) Study on the catastrophic collapse of surface land induced by mining under a shallow and hard strata. J China Coal Soc 10:1051-1056

Wang XJ, Hu ZQ, Hu QF, Chen C (2015) Evolution and self-healing characteristic of land ecological environment due to super-large coalface mining in windy and sandy region. J China Coal Soc 9:2166-2172

Wu K, Ge JX, Wang LD, Zhou M (2010) Integrated technology of mining subsidence. China University of Mining and Technology Press, Xuzhou

Xiao W, Hu ZQ (2014) GIS-based pre-mining land damage assessment for underground coal mines in high groundwater area. Int J Min Miner Eng 5(3):245-255

Xiao W, Hu ZQ, Chugh YP, Zhao YL (2014a) Dynamic subsidence simulation and topsoil removal strategy in high-groundwater table and underground coal mining area-a case study in Shandong Province. Int J Min Reclam Environ 28(4):250-263

Xiao W, Hu ZQ, Fu YH (2014b) Zoning of land reclamation in Coal mining area and new progresses for the past 10 years. Int $\mathrm{J}$ Coal Sci Technol 1(3):177-183

Wang XJ (2014) Monitoring, evolution and self-healing characteristic of land damage due to high tension coal mining in windy and sandy area. China University of Mining and Technology (Beijing), Beijing

Xu YN, He F, Wu ZS, Yuan HC (2005) Prediction of mining cave-in index of Shendong coal-mine area. China Coal 12:37-40,43

Xuan YQ (2008) Research on movement and evolution law of breaking of overlying strata in shallow coal seam with a thin bedrock. Rock Soil Mech 2:512-516

Yi MS (2008) Study and application of key strata theory in shallow seam of Shendong mining area. China University of Mining and Technology, Xuzhou

Zhang YJ, Li FM (2011) Monitoring analysis of fissure development evolution and height of overburden failure of high tension fullymechanized caving mining. China J Rock Mech Eng 30(s1):2294-2301

Zhang JM, Li P, Gao L (2013) Research on structural damage of mining overburden rock of oversized fully mechanized coal mining face. Shenhua Sci Technol 4:20-23

Zhang DS, Fan GW, Ma LQ, Wang XF (2011) Aquifer protection during longwall mining of shallow coal seams: a case study in the Shendong Coalfield of China. Int $J$ Coal Geol 86(2-3):190-196

Zou YF, Deng KZ, Ma WM (2003) Mining subsidence engineering. China University of Mining and Technology Press, Xuzhou 